ARXIU D'ETNOGRAFIA DE CATALUNYA, N. 3, 1984

\title{
LOS FINQUEROS Y EL USO DEL TRABAJO FORZADO EN LA AGRICULTURA COLONIAL DE LA ISLA DE FERNANDO POO
}

\author{
Gonzalo SANZ CASAS \\ Departament d'Antropologia Cultural, \\ Facultat de Geografia i Història. U.B. \\ Institut Català d'Antropologia.
}




\section{Introducción}

Este artículo analiza el reclutamiento y el trabajo forzados como formas de obtención y de explotación del trabajo indígena en la agricultura colonial de la isla de Fernando Poo, durante los primeros años de este siglo. En las páginas siguientes, describo algunas de las características de la colonia de Fernando Poo y, a continuación, intento mostrar qué factores influyeron en la decisión de los finqueros coloniales en favor del trabajo forzado. Admitiendo la especificidad de las diversas experiencias coloniales en el África, el uso de trabajadores forzados en la agricultura colonial de Fernando Poo fue una forma de explotación del trabajo, alternativa al trabajo asalariado, que tenía como objetivo incrementar la oferta de trabajo y reducir los costes de la mano de obra y de la producción agrícola en el marco de unas relaciones de producción de tipo capitalista.

\section{Algunas notas sobre la historia colonial de Fernando Poo}

A fines del siglo XIX, un plan de colonización del Ministerio de Ultramar ${ }^{1}$ trataba de recuperar del olvido la colonia de Fernando Poo y sus dependencias, ${ }^{2}$ unos enclaves que habían permanecido al margen de los intereses coloniales españoles, desde su cesión por Portugal a España en 1778. La atención gubernamental por los territorios de Guinea no pretendía en modo alguno rivalizar con las potencias europeas en la expansión colonial en el África, sino ante todo neutralizar las amenazas de ese expansionismo sobre las posiciones españolas en el golfo de Biafra. Con la prioridad de este objetivo, la isla recibió mayor atención presupuestaria y el gobierno español, dispuesto a rentabilizar las posibilidades comerciales y agrícolas de la colonia, inició una amplia campaña de promoción de la isla para conseguir la emigración de población y de capital procedentes de la metrópoli a la colonia.

Las promesas gubernamentales se concretaron en una mayor presencia militar y administrativa en la isla, en el establecimiento a partir de 1887 de un correo marítimo regular entre la metrópoli y la colonia, en el baio 
precio de la tierra y en las facilidades para la inmigración y el asentamiento de colonos, lograron atraer a unos cientos de colonos que, en su mayoría con escaso capital, adquirieron tierras para el cultivo agrícola y/o fundaron establecimientos comerciales en los pocos núcleos de colonización de la isla Sin embargo, el relativo éxito de la campaña de promoción de la colonia propagado por el optimismo de los círculos africanistas españoles, que bautizaban a Fernando Poo como la "nueva Cuba», no logró atraer a los capitales de la metrópoli. Para éstos, y también para amplios sectores de la opinión pública española, Fernando Poo seguía siendo una isla insalubre y perniciosa para la población blanca, como lo habían demostrado los fracasados asentamientos de colonos a mediados del siglo $\mathrm{xIX}^{3} \mathrm{y}$, además, Fernando Poo no era una colonia, sino más bien un lugar de deportación adonde eran condenados presos políticos y delincuentes. ${ }^{4}$

La decadencia social y económica de Fernando Poo no era la confirmación de las limitadas posibilidades de la isla como colonia de explotación agrícola y comercial, tal y como aseguraban los detractores de la colonización de la isla, sino consecuencia de la política colonial española ejercida en la isla desde mediados del siglo xIx. Desde finales del siglo xvIII Fernando Poo, una isla de 2.034 kilómetros cuadrados y situada frente a la desembocadura del río Níger, se convirtió bajo la influencia británica en una base de operaciones de la escuadra antiesclavista y en un centro de importantes actividades en el golfo de Biafra. Su capital, Santa Isabel, fundada por los ingleses con el nombre de Clarence City en 1827, acogió a una heterogénea población multirracial integrada por una minoría de población blanca, por inmigrantes naturales de las Antillas, por población procedente de las colonias británicas y de distintos puntos de la costa occidental de África. Una minoría de esta población, vinculada cultural y económicamente al ámbito colonial británico y dedicada con preferencia al tráfico comercial del aceite de palma, se erigió en la élite social y económica de Santa Isabel, que, en los años sesenta y setenta del pasado siglo, siguiendo el ejemplo de las plantaciones de cacao en la vecina isla portuguesa de São Tomé, inició los primeros cultivos del cacao en Fernando Poo.

El anterior auge social y económico de Fernando Poo contrastaba, a finales de siglo, con las noticias acerca de los muchos defectos e insuficiencias que presentaba la colonización en la isla: los abastecimientos de productos básicos desde la metrópoli eran irregulares y escasos, las condiciones sanitarias de la colonia eran precarias e insuficientes, los centros de colonización de la isla estaban incomunicados por la inexistencia de una red interior de tránsito, los viajeros y las mercancías circulaban por los caminos indígenas y por vía marítima bordeando el litoral en pequeños botes a remo $\mathrm{y} / \mathrm{o}$ a vela, el gobierno incumplia las promesas de ayuda económica a los colonos inmigrados y ni la agricultura ni el comercio ofrecían el floreciente aspecto y volumen de negocios, que tanto pregonaba la propaganda oficial.

Pese a todo ello, la promoción de la colonia había logrado algunos resultados esperanzadores. Las nuevas fincas de los colonos recién inmigrados proliferaban rápidamente junto a las viejas plantaciones de los antiguos coloniales en los alrededores de Santa Isabel y, más tarde, en las bahías de San Carlos y de Concepción. Entre 1899 y 1909 las concesiones de tierras en Fernando Poo pasaron de 8.696 a 13.233 hectáreas y los terrenos en cultivo, para esas mismas fechas, aumentaron de 2.166 a 11.320 hectáreas. ${ }^{5}$ Pero ni el notable aumento de la propiedad y del cultivo agrícolas, ni las 1.128 toneladas de cacao exportadas en 1901 podían ocultar la realidad del estado de la agricultura colonial en la isla. La mayoría de los informes oficiales y privados relativos al cultivo agrícola en Fernando Poo coincidían en señalar la generalización de técnicas agrícolas defectuosas, la baja productividad en las fincas y el incremento de las propiedades sin cultivar: en 1899 se estimaba que de las casi 8.700 hectáreas de terreno agrícola concedidas, sólo unas 450 estaban en plena producción, otras 700 hectáreas empezaban a producir y el resto estaba sin cultivar. El calamitoso estado que of recían las fincas agrícolas coloniales, dedicadas mayoritariamente al monocultivo del cacao, era consecuencia de la inexperiencia agrícola y de la falta de capital líquido de muchos finqueros para atender sus plantaciones; también del atraso general de la colonización en la isla imputable en este caso a la administración colonial; pero, sobre todo, de la escasez de mano de obra para satisfacer la demanda de trabajo en la agricultura colonial. Si hasta entonces la demanda de mano de obra había sido cubierta con la contratación de trabajadores procedentes de distintos mercados de trabajo del África occidental (Sierra Leona, Liberia, etc.), con braceros naturales de la zona continental de la colonia (Río Muni) y con el trabajo ocasional de braceros bubis, población autóctona de la isla; a principios de siglo, la expansión de la agricultura colonial favorecida por una indiscriminada política de concesión de tierras era frenada por el déficit de mano de obra para atender el trabajo en las plantaciones agrícolas coloniales.

El trabajo inmigrante, cada vez más caro y de difícil adquisición a causa del precio y de las restricciones a la movilidad del trabajo en las colonias hasta entonces suministradoras de trabajadores a la agricultura fernandina, hizo más acuciante el déficit de trabajo. Los efectos de la prohibición británica a sus trabajadores de emigrar a Fernando Poo y el fuerte aumento en el precio de los braceros liberianos sumieron a la agricultura colonial de Fernando Poo en una profunda depresión económica. La inexistencia de un 
sistema de crédito oficial capaz de paliar la falta de capital de muchos finqueros y la incapacidad económica de éstos para hacer frente al alza en el coste de la mano de obra inmigrante, amenazaban el futuro de la agricultura colonial en la isla por la escasez de mano de obra tal y como declaraba, en 1908, un plantador de la isla: «Tener fincas o terrenos en Fernando Poo y no tener braceros para trabajarlas y recoger las cosechas, es lo mismo que tener oro en una isla desiertas.

La escasez de mano de obra en la colonia y la dependencia de la agricultura colonial respecto a los trabajadores procedentes de mercados de trabajo externos a la colonia eran cuestiones que remitían, en última instancia, a la inexistencia de un mercado de trabajo en la colonia al servicio de una agricultura comercial en expansión.

La no formación de un mercado de trabajo en Fernando Poo y el reclutamiento forzado de la población indigena

Para muchos finqueros coloniales la política colonial tenía una parte importante de responsabilidad en el déficit de mano de obra porque, según afirmaban algunos coloniales, la colonización en Fernando Poo se caracterizaba «... por la incuria de nuestra administración colonial, por nuestros procedimientos colonizadores, llenos de sensiblerías y de debilidades, de tolerancias y de utopías»?

Razones económicas y políticas, más que estrictamente ideológicas (como, por ejemplo, la invocada fidelidad a la tradición colonial española en Hispanoamérica), explican las dificultades para la formación de un mercado de trabajo en Fernando Poo. Por una parte, la política colonial favorecía la expansión de la pequeña propiedad agrícola porque ésta exigía un desembolso de capital poco importante, una moderada demanda de mano de obra indígena y ofrecía mayores garantías para la continuidad de las explotaciones agrícolas. Así, aquellos proyectos de colonización económica que solicitaban la ocupación de considerables extensiones de tierra e implicaban una mayor demanda de trabajo indígena, eran rechazados porque representaban un incremento presupuestario de la administración colonial para la efectiva ocupación militar y el control administrativo de la colonia. Por ótra, el reconocimiento de la propiedad indígena que impedía la concesión de grandes extensiones de tierras porque significaba despojar a la población indígena de sus tierras, ${ }^{8}$ ocultaba problemas más graves: en la isla de Fernando Poo, a finales del siglo xIx, el Ministerio de Estado recomendaba no conceder grandes extensiones de tierra a los colonos porque $« \ldots$ podría traer consigo graves consecuencias para nuestro dominion ${ }^{9}$; y en la zona continental de la colonia, bajo «soberanía» española después del Tratado de París en 1900, el control político y administrativo se limitaba a unos pocos enclaves costeros.

Así, la combinación de factores políticos, económicos e ideológicos, aunque estos últimos de menor importancia que los anteriores, tendían a asegurar la tenencia de la tierra. El régimen de la propiedad de la tierra reconocía jurídicamente la propiedad indígena y facilitaba a los finqueros el acceso a la propiedad de pequeñas fincas. La relativa abundancia de tierra disponible para el cultivo y el régimen de la propiedad favorable a la expansión de pequeñas y medianas explotaciones agrícolas, anulaban los efectos de la competencia por la escasez de la tierra, moderaban el alza de las rentas agrarias $y$, ante la inexistencia de población indígena sin tierras, la escasez de trabajo en las plantaciones agrícolas coloniales se convertía en crónica.

Frente a esta situación, y pese a que los coloniales imputaban a la politica colonial muchos de los problemas con que se enfrentaba la colonización en Fernando Poo y, en particular, el déficit de mano de obra, los finqueros coloniales optaron por desencadenar una incesante campaña de desprestigio $\mathrm{y}$ acusaciones contra la población indígena, y no por presionar a la administración colonial para que ésta modificara las directrices de la política colonial. Una amplia literatura colonial aludió, con insistencia, a la natural apatía y poco amor al trabajo de la población indígena. De este modo, la población colonial convirtió a la población indígena, a su organización social y política y a sus formas de vida, en la causa principal de la crisis económica en la agricultura colonial y de las desventuras y fracasadas ilusiones de los finqueros. Para la mayoría de éstos, la escasez de mano de obra tenía su razón de ser en la resistencia de la población indígena a la asalarización. Una resistencia que, como señalaba un funcionario colonial, no era posible vencer «... por más que para conseguirlo se les hagan proposiciones más ventajosasm..$^{10}$

El autor de la cita anterior se equivocaba al apuntar las causas de la no salarización de la población indígena. En el marco específico de la expansión del monocultivo del cacao en Fernando Poo, lo que merecía atención no era la insistente confirmación de la «tenaz» resistencia de la población indígena a la salarización, sino preguntarse por qué la población indígena no acudía a trabajar en las fincas coloniales. Una política colonial desfasada en el tiempo y en contradicción con los objetivos previstos era, en gran medida, responsable de la escasez de trabajo en la agricultura colonial; pero también el comportamiento de muchos finqueros coloniales contribuía a la negativa de la población indígena a la salarización. Respecto a este punto, el gobernador L. Ramos Izquierdo escribía en 1912: el bubi «... rinde 
trabajo en condiciones aceptables y concurre a trabajar en las plantaciones de los colonos siempre y cuando sea bien tratado por éstos y satisfecho en su jornal y ración...."; "... si los bubis en general no concurrían a trabajar en las plantaciones de los colonos es porque algunos de éstos no cumplían con ellos sus contratos...n." No se trataba de acontecimientos excepcionales. El incumplimiento de los contratos y los malos tratos recibidos por los trabajadores habían provocado, en 1900, la revuelta de seiscientos braceros nigerianos empleados en las fincas coloniales de Fernando Poo.

La escasez de mano de obra, como reconocía la administración colonial, radicaba en \&... que la iniciativa de los particulares no es bastante a conseguir el número de braceros necesariosn. ${ }^{12}$ La campaña de opinión de los finqueros coloniales responsabilizando a la población indígena del déficit de trabajadores en las plantaciones agrícolas coloniales, era la confirmación por parte de los coloniales de su propia incapacidad económica y política para superar las causas que provocaban la escasez de mano de obra: por una parte, la falta de capital de los finqueros para pagar los braceros necesarios en la agricultura colonial y, por otra, los efectos de la legislación colonial que obstaculizaban la formación de un mercado de trabajo en la colonia. La responsabilidad en la no formación de un mercado de trabajo en Fernando Poo no era exclusiva de la administración colonial; los finqueros coloniales estaban dispuestos a moderar sus críticas a la gestión de la administración colonial, a cambio de la intervención del aparato militar-administrativo de la colonia en la obtención de trabajadores abundantes y económicamente más baratos.

En la isla de Fernando Poo, con una agricultura que exigía una considerable demanda de mano de obra, cabe preguntarse por qué los finqueros coloniales optaron por el uso del trabajo forzado como alternativa al trabajo asalariado.

A continuación, plantearé dos cuestiones referentes al trabajo forzado como forma de uso de la fuerza de trabajo en la agricultura colonial de Fernando Poo. En primer lugar, ¿la elección de los finqueros coloniales en favor del trabajo forzado fue una decisión de carácter estrictamente económica, o dependió también de la influencia de factores no económicos? Y, en segundo lugar, ¿el trabajo forzado fue la forma de explotación del trabajo más barata económicamente, garantizó un regular rendimiento del trabajo y solucionó el déficit de mano de obra en las plantaciones coloniales de Fernando Poo?

Lo que precisa explicación es el por qué los finqueros coloniales decidieron cubrir el déficit de trabajadores y reducir el coste del trabajo asalariado con trabajo forzado y no con otras formas de empleo del trabajo, como arrendatarios o aparceros que posibilitan un mayor y mejor aprovechamiento del trabajo empleado - incluido el de la familia del trabajador- y ofrecen mayores garantías para la solución de la escasez de trabajo. J. Martínez Alier en sus trabajos sobre la agricultura en la Sierra del Perú, en Cuba y en Andalucía, señala que las decisiones de los propietarios en materia de empleo de la fuerza de trabajo no dependen exclusivamente de las rentas o beneficios que pueden obtener con un tipo u otro de empleo de trabajo, sino también del peso específico de los factores no económicos en la elección. ${ }^{13}$ Además, la racionalización en el empleo de la fuerza de trabajo es una decisión que exige cierta integración económica y política de los propietarios como clase social. En la agricultura colonial de Fernando Poo, la escasez de trabajo y el elevado coste de la mano de obra inmigrante no tuvo estos efectos integradores. Los reclutadores, el capital usurero $\mathrm{y}$ algunos grandes propietarios, cuyo poder de influencia dominaba la opinión y las decisiones de los finqueros, podían no estar interesados en la sustitución del trabajo asalariado, porque su escasez favorecía la especulación y la posibilidad de incrementar sus ganancias y sus propiedades a costa de la extorsión de los pequeños finqueros. Baste al respecto la cita siguiente: $\alpha \ldots$ muchos de aquellos agricultores estaban envueltos en las gatras de la usura, en atención a que existiendo un núcleo de pequeños agricultores que representaban una gran parte de las plantaciones de cacao... no contaban con capital...». «De ahí que muchos pequeños agricultores hubiesen sucumbido y otros estuviesen próximos a sufrir igual suerten. ${ }^{14}$

Fernando Poo era una sociedad estratificada sobre la base del control de los recursos estratégicos y del prestigio social derivado de ese control. El dominio de los recursos económicos y del estatus social era la expresión de unos valores culturales gestados por una minoría de población que se había consolidado, al mismo tiempo, que la sociedad colonial. Grandes plantadores, comerciantes, prestamistas, altos funcionarios de la administración colonial, misioneros, empleados de factoría, militares, capataces de plantación, pequeños finqueros, etc., constituían esta población colonial que se definía más por su adscripción a unas actividades económicas, unas prácticas sociales y culturales, que por su origen racial.

La lucha de esta población por lograr un mayor control de los recursos económicos y por mejorar su estatus social convertía a Fernando Poo en una sociedad altamente competitiva; una competencia que, al arruinar a muchos y enriquecer a unos pocos, obstaculizaba la cohesión interna como grupo social basada en identidades étnicas, culturales o de otro tipo. La ansiedad por hacer realidad las expectativas individuales era una de las causs de la inestabilidad social en la colonia, que se manifestaba en las acciones de los individuos y en las relaciones interpersonales. Así, el conflicto presidía la 
vida cotidiana y la violencia física y psicológica caracterizaba las relaciones sociales que precisaban, para su supervivencia, de la intransigencia de un discurso ideológico y cultural que tenía como principal objetivo la legitimación de los más privilegiados en el poder.

Esta violencia, que se proyectaba de forma indiscriminada, se ejercía con especial intensidad sobre los agricultores de subsistencia, los cazadores, los empleados y braceros de plantación, los porteadores, los criados, etc. El colonial despreciaba la cultura y la condición étnica del africano porque, para aquél, eran las causas principales de la actitud refractaria del indígena hacia los valores de la sociedad colonial; pero, también, menospreciaba el trabajo del bracero, del porteador, del criado, etc., porque eran ocupaciones que se atribuían a la población de raza negra por su reconocida «inferioridad» biológica y cultural. El colonial era «superior» y, precisamente, esta preeminencia autootorgada se legitimaba biológica y culturalmente. Su estatus social estaba asociado a la condición de propietario, de patrón, de empleador y en modo alguno a la condición de asalariado, de trabajador manual. El origen socioeconómico de muchos finqueros explicaba también el desprecio de la condición de bracero por parte de aquéllos: en muchos casos campesinos pobres, sin tierras, que inmigrados a la colonia se convertían en propietarios agrícolas y en la élite social de la nueva sociedad. El finquero, hambriento de tierra y al mismo tiempo inexperto como propietario y empleador, depositaba su confianza en la experiencia de los antiguos coloniales. Ambos participaban de una misma ideología que, alimentada por una sobrevaloración social de la condición de propietario de la tierra, proyectaba una definición cultural del trabajador indígena que afirmaba la incapacidad técnica de éste como campesino arrendatario o aparcero y lo adscribía como bracero en la división social del trabajo. El rechazo de otras formas de empleo del trabajo y la solicitud del trabajo forzado eran también el resultado de una legislación colonial, como el régimen de la propiedad indígena que limitaba la movilidad del trabajo, que repercutía en las decisiones de los finqueros sobre el empleo de la fuerza de trabajo; de las presiones existentes entre los propios finqueros pero, sobre todo, de la interiorización de la ideología del trabajo forzado que tenía sus precedentes más inmediatos en la tradición colonial de las formas del trabajo esclavo y semiesclavista en el África occidental. El reclutamiento forzado de la población indígena no era una decisión excepcional, ni atípica, ni desconocida: el éxito de las plantaciones de cacao en las colonias portuguesas de São Tomé y de Príncipe con el uso de trabajadores forzados reclutados en Angola constituía, para los finqueros de Fernando Poo, un ejemplo a imitar.
Para los finqueros coloniales de Fernando Poo, pretender del desarrollc de los cultivos de exportación con trabajo asalariado inmigrante era, dadas las circunstancias, un contrasentido económicamente muy costoso cuando, en la propia colonia, podian obtenerse trabajadores a unos costes notablemente inferiores: en 1898, el coste de un trabajador liberiano a razón de cuatro pesos mensuales ascendía a 453,80 pesetas por año de contrato. ${ }^{15}$ En cambio, la prestación personal obligatoria al trabajo en las plantaciones coloniales afectaba a todos los bubis en edad comprendida entre 15 y 60 años, que carecían de título de la propiedad y no se ocupaban en cargos retribuidos con un salario. La población bubi era reclutada de julio a septiembre, el trabajador reclutado según la ley recibía un salario de una peseta —que incluía la ración alimenticia- por jornada laboral de diez horas. ${ }^{16} \mathrm{La}$ imposición del trabajo forzado a la población indígena era una forma de obtener mano de obra barata y, también, de superar la ruinosa economía de muchos finqueros coloniales. Además, el trabajo forzado era una alternativa demográficamente posible: no sólo se contaba con la población bubi de Fernando Poo, sino sobre todo, la población del territorio continental de la colonia (Río Muni) podía convertirse en una reserva de mano de obra al servicio de la economía agrícola de la isla.

Sin embargo, el trabajo forzado deterioró notablemente las relaciones entre los finqueros y los braceros: así, el número de trabajadores fugados de las fincas agrícolas aumentó, las protestas de los braceros por la precariedad de las condiciones de trabajo - malos'tratos, insuficiencia de las raciones alimenticias, etc.- se intensificaron, las formas de resistencia de los trabajadores repercutieron en las labores agrícolas y en el rendimiento del trabajo, los indices de enfermedad y de mortalidad entre los braceros se incrementaron y la necesidad de un mayor control del trabajo y de la disciplina laboral sumó nuevos gastos a la economía de los finqueros coloniales.

Pese a todo, la prestación personal obligatoria al trabajo en las fincas agrícolas coloniales para la población indígena fue impuesta como terapia para «... estas razas que viven en la más completa holganza por no dejarse el hambre sentir en ellas, en razón a que a su derredor produce esta fértil tierra cuanto necesitan para atender aquélla, se vayan habituando al trabajo y convertirse en seres productoresn. ${ }^{17}$ Esta declaración del gobierno general de la colonia, que encabezaba el decreto regulador del trabajo forzado, inauguraba una etapa de más estrecha colaboración entre las autoridades coloniales y los finqueros. La administración colonial, hasta entonces explícitamente reacia a intervenir en las relaciones laborales, aceptaba las demandas de los finqueros en favor del trabajo forzado y ponía al servicio de éstos a la guardia colonial para la recluta de la población indígena. A cambio, los fin- 
queros aceptaron muchas de las deficiencias de la organización administrativa de la colonia y contribuyeron a sufragar, mediante impuestos, los gastos económicos ocasionados por la intervención militar en la prestación personal al trabajo de la población indígena. En definitiva, el pacto entre las autoridades coloniales y los finqueros era un intento de solucionar la crisis económica a costa de la población indígena.

Los abusos de los guardias colonias en las reclutas y de los finqueros en el trato dado a los trabajadores forzados provocaron, en 1910, la insurrección armada del poblado de Balachá. ${ }^{18}$ La represión de la revuelta bubi fue rápidamente sofocada, el poder colonial aprovechó los acontecimientos para consolidarse en la isla y, con él, las reclutas forzadas de la población indigena y la disciplina laboral cobraron intensidad. En los círculos africanistas, la revuelta de Balachá fue calificada de «guerra bubi»; por fin, a ejemplo de las potencias coloniales europeas, España tenía su «guerra colonial» en el África negra. Para otros, la sublevación bubi era un aviso de que el trabajo forzado no era la terapia más adecuada: «Creemos que el trabajo bubi retribuido, no el que se alcance por la prestación personal, será un buen elemento reformador de la mano de obra y un medio práctico de atracción de la raza bubin. ${ }^{19}$

En efecto, a corto plazo, el reclutamiento forzado de la población bubi $y$, en menor medida, la inmigración forzada de trabajadores procedentes de Río Muni, lograron cubrir la demanda de mano de obra en las plantaciones coloniales de la isla; pero, a largo plazo, los efectos del trabajo forzado repercutieron negativamente en la población reclutada y, en particular, sobre la población bubi: una profunda crisis demográfica causada por diversas epidemias (viruela, tos ferina, disentería, etc.), agravada por las repercusiones del trabajo forzado, asoló a la comunidad bubi incapacitándola demográficamente para satisfacer por cualquier método la demanda de trabajo en la agricultura colonial. ${ }^{20}$ Pero si en la isla la escasez de trabajo era consecuencia de la crisis demográfica de la población bubi, las esperanzas de los finqueros coloniales estaban depositadas en los recursos demográficos de Río Muni, para el que solicitaban la definitiva ocupación militar del territorio como solución del problema bracero. Ahora bien, en la zona continental de la colonia el acceso al potencial mercado de trabajo, abundante y barato, dependía del efectivo control administrativo y militar del territorio y de su población: una vez esquilmadas las áreas costeras, las dificultades para conseguir trabajadores aumentaban a medida que las expediciones de militares y reclutadores penetraban en el interior y se revelaban impotentes para someter la resistencia de los poblados fang. Así, la crisis demográfica de la población bubi y la incapacidad militar de la administración colonial para cubrir la demanda de mano de obra con trabajadores procedentes de Río Muni obligaron, en 1913, a negociar un acuerdo para la inmigración de trabajadores liberianos a Fernando Poo. ${ }^{21}$ La firma del Tratado con Liberia advertía del relativo fracaso del trabajo forzado por razones demográficas, políticas y militares para proporcionar la mano de obra necesaria para atender el trabajo en las 10.000 hectáreas en cultivo de la isla de Fernando Poo. Sólo a finales de la década de los años veinte, una mayor presencia militar logró satisfacer, mediante el reclutamiento forzado, la demanda de mano de obra en la agricultura colonial de Fernando Poo, cubierta desde 1913 en su mayoría por trabajadores liberianos, con el trabajo forzado de la población bubi y con la sistemática emigración forzada de trabajadores procedentes de Río Muni.

\section{Conclusiones}

La generalización del trabajo forzado en el África colonial plantea algunas cuestiones que han sido objeto de reflexión teórica. Por una parte, algunos autores interpretan que el trabajo forzado fue consecuencia de ciertas ideologías coloniales «caducas», que precisaban de la coerción física de la población indígena para obtener la mano de obra y de la implantación de formas semiesclavistas del trabajo para la expansión de las economías coloniales. Así, ciertas experiencias coloniales, como la portuguesa en el África subsahariana, constituyen evidencias históricas de este tipo de política colonial, que renunció al libre desarrollo de las leyes de la economía capitalista que en modo alguno precisan de la intervención de mecanismos extraeconómicos para lograr el desarrollo de la economía capitalista. ${ }^{2}$ Por otra parte, y en oposición a la teoría antes expuesta, algunas tesis identifican las formas de explotación del trabajo con los sistemas socioeconómicos históricamente dados. En este sentido, una excesiva fidelidad a esta identificación puede provocar algunos abusos y simplificaciones. La cuestión es que el trabajo forzado no es una forma de explotación del trabajo «atípica» del capitalismo aunque, sin duda, la expansión de los países europeos a finales del siglo XIX tuvo un carácter capitalista. Pero, es posible reconducir el problema: el trabajo forzado fue la expresión de una fase de transición hacia la definitiva consolidación del capitalismo en aquellas formaciones sociales dominadas por modos de producción precapitalistas. Así, el trabajo forzado es interpretado como la respuesta de un "modo de producción colonial», de transición, a la resistencia de la sociedad precapitalista a la expansión del capitalismo. Y, en definitiva, la generalización del trabajo forzado se presenta 
como una necesidad histórica que antecedió al pleno desarrollo del capitalismo y a su forma de explotación del trabajo «típica», el trabajo libre. ${ }^{23}$

No comparto plenamente ninguna de las dos interpretaciones antes expuestas. En primer lugar, pienso que a priori los empleadores de trabajo no adoptan una u otra forma de explotación del trabajo atendiendo a razones o a principios de la economía política. Y, en segundo lugar, la elección de un sistema de trabajo depende de factores como los costes de la producción, pero también de la ideología de los empleadores de trabajo y de la interacción entre las acciones de los empleadores y las respuestas de los trabajadores, en el marco de las circunstancias políticas y económicas en que se desenvuelven. ${ }^{24}$

Los finqueros coloniales de Fernando Poo eligieron el trabajo forzado de la población indígena no por el carácter «atrasado» de la colonización española y de los propios finqueros, ni tampoco para quebrar la tenaz resistencia de las comunidades indígenas a la consolidación del capitalismo. Los finqueros coloniales, frente al escaso y caro trabajo asalariado, prefirieron el reclutamiento forzado de los trabajadores porque era una entre las diversas formas de obtención y explotación del trabajo, y no fueron menos capitalistas por preferir un trabajo económicamente más barato. Ahora bien, varios factores influyeron en la decisión de los empleadores en favor del trabajo forzado: los efectos del régimen de la propiedad de la tierra en la movilidad de la mano de obra; la inexistencia de un sistema de crédito oficial capaz de financiar la economía de las plantaciones coloniales; la precariedad económica de los finqueros para hacer frente al coste del trabajo asalariado; la interiorización de la ideología del trabajo esclavo como forma de uso del trabajo indigena; la falta de cohesión social entre los finqueros coloniales para lograr una racionalización en el empleo del trabajo y, sobre todo, la inexperiencia de los finqueros coloniales como propietarios de la tierra y como empleadores de trabajo.

Así, la combinación de factores económicos y extraeconómicos contribuyó a rechazar otras formas de empleo del trabajo, también alternativas al trabajo asalariado, e influyeron en la preferencia de los finqueros coloniales por el trabajo forzado. A principios de siglo la expansión del monocultivo del cacao en Fernando Poo se realizó sobre la base de unas relaciones de producción capitalistas que adoptaron diversas formas de explotación de la fuerza de trabajo y, entre éstas, predominó durante años el trabajo asalariado como un de las elegidas por los finqueros coloniales para superar la escasez y el elevado coste del trabajo asalariado.
1. Reales decretos del 26 de noviembre 1880 , del 24 de diciembre 1894 y del 11 de julio de 1904.

2. Por el tratado hispano-portugués de El Pardo en marzo de 1778, Portugal cedió a España las islas de Fernando Poo, Annobón y el derecho a negociar en las costas opuestas a Fernando Poo, La diplomacia española, alegando las cláusulas del tratado de 1778 , reivindicó sin éxito el derecho de soberanía sobre una amplia zona costera continental comprendida entre el cabo Formoso y el río Gabón. El Tratado de París en 1900 puso fin al contencioso fronterizo hispano-francés en El Muni y delimitó la zona continental bajo soberanía española (Río Muni) a una extensión de 24.000 kilómetros cuadrados. Definitivamente, los territorios españoles en el golfo de Guinea comprendieron: las islas de Fernando Poo, Annobón, los islotes de Elobey Grande y Elobey Chico, y, en el continente, Río Muni.

3. Una primera aproximación a este tema ha sido tratada en mi tesis doctoral: Política colonial y organización del trabajo en la isla de Fernando Poo: 1880-1930. Universidad de Barcelona, 1984, pp. 31-45.

4. Consultar, entre otros, F. I. BALmaSeda: Los confinados a Fernando Poo $e \mathrm{im}$ presiones de un viaje a Guinea, Nueva York, 1869; F. LAstres: La colonización penitenciaria de las Marianas en Fernando Poo. Horrores de la Dominación Española, La Habana, 1898, y, también, A. DE Unzueta: Historia geográfica de la isla de Fernando Poo, Madrid, 1947.

5. Archivo General de la Administración, Sección Presidencia del Gobierno, legajo 31 , expediente $n 0^{\circ} 12.163$, y legajo 20 , expediente n. 8.761 .

6. A. PéreZ: «El problema bracerow, en Tercer Congreso Africanista, Barcelona, 1909, p. LVL.

7. G. Granados: Páginas sueltas sobre la Guinea Española, Barcelona, 1912, p. 26.

8. Reales decretos del 11 de julio de 1904 y del 11 de enero de 1905.

9. Archivo Histórico Nacional, Sección Ultramar, legajo $5.314^{2}$, expediente n.* 506.

10. J. Ruiz у Aвауа: Descripción de los cultivos que se practican en las llamadas fincas de la isla de Fernando Poo, Cádiz, 1898, p. 14.

11. L. RAMos IzouIERDo: Descripción geográfica y gobierno, administración y colonización de las Colonias españolas del Golfo de Guinea, Madrid, 1912, p. 34.

12. Bando del Gobierno General de la Colonia, del 31 de agosto 1907. 1977.

14. L. Ramos Izouierdo, ob. cit., p. 205.

15. J. Ruiz y AlbaYA, ob. cit., pp. 14-15.

16. Bando del Gobierno General de la Colonia, del 30 de agosto 1907

17. Bando del Gobierno General de la Colonia, del 21 de abril 1908.

18. F. DEL Río JonN: Africa Occidental Española (Sáhara y Guinea), Madrid, p. 187

20. Para la segunda mitad del siglo xix la población bubi oscila, según los auto res, entre un máximo de 30.000 y un mínimo de 15.000 habitantes, Los misioneros claretianos censaron en el año 1900, con ciertas bubis. Pese a livaras garantias de veracidad, unos 14.816 de los autores a diversidad de las cifras de población bubi que se barajan, la mayoría siglo xx. Asi, los 6.800 la espectacular caída demográfica en las primeras décadas del siglo xx. Así, los 6.800 bubis censados por L. RAMos Izouiterdo para el año 1906 y que G. TessmanN, en Die Bubi auf Fernando Poo, Berlín, 1923, eleva a 8.000 bubis, señalan el tono dramático de la crisis demográfica de la población bubi. 
21. Consultar, en particular, para la parte liberiana los trabajos de I. K. Sundiata: «Prelude to Scandal: Liberia and Fernando Poo, 1880-1930s, Journal of African History, 1974, VX, pp. 97-112; y Black Scandal, ISHI, 1980.

22. Ver, entre otros, los trabajos de R. J. HAMmond: Portugal and Africa: 1815 1910, Stanford, 1966; y M. BARRAT Brown: La teoría económica del imperialismo, Madrid, 1975.

23. En un artículo ya clásico sobre la economía rodhesiana, G. ARRigHi advierte de la positiva respuesta del campesinado africano a los estímulos del mercado, lo que no impidió, por otra perte, la imposición de mecanismos de coerción extraeconómica ( La oferta de trabajo en una perspectiva histórica», Colonos, campesinos y multinacionales, Madrid, 1975). ¿Basta como hace P.Ph. REY para generalizar la resistencia de los modos de producción precapitalistas al capitalismo, con citar los comentarios de Marx sobre la estrecha compenetració de la agricultura tradicional y el artesanado rural, que caracteriza al llamado «modo de producción asiático» y su capacidad de oposición al capitalismo, o con recordar el capítulo de El Capital dedicado a la acumulación primitiva?, ¿no hay en algunos sectores africanistas franceses, como apunta la introducción a African Labour History $(1978$, p. 22$)$ un desmesurado interés por el precapitalismo en detrimento del estudio de la historia del capitalismo en África? Sobrebre la obra de P.Ph. ReY pueden consultarse, entre otros, Colonialisme, néocolonialisme et transition au capitalisme, París, 1971; y Les alliances de classes, París, 1976.

24. V. Stolcke and M. Hall: "The Introduction of Free Labour into to São Paulo Coffee Plantationsw, The Sex Division of Labour, Development and Women's Status (no publicado), 1980. 